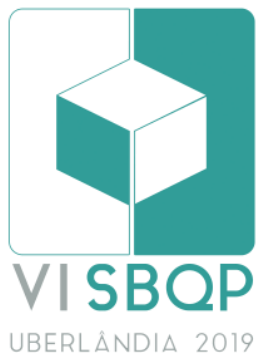

\title{
VITALIDADE EM ESPAÇOS PÚBLICOS NA CIDADE DE JUIZ DE FORA
}

\author{
BERALDO, Eduarda \\ Universidade Federal de Juiz de Fora, e-mail: eduardabottiberaldo@gmail.com \\ SENRA, Silvia \\ Universidade Federal de Juiz de Fora, e-mail: sil.senra@gmail.com \\ CASSANI, Maria \\ Universidade Federal de Juiz de Fora, e-mail: maria.cassani.5@gmail.com \\ ALBERTO, KIaus \\ Universidade Federal de Juiz de Fora, e-mail: klaus.alberto@ufjf.edu.br \\ GONÇALVES, Anna \\ Universidade Federal de Juiz de Fora, e-mail: anna.ribeirog@outook.com \\ NERY, Letícia \\ Universidade Federal de Juiz de Fora, e-mail: leticianery.designer@gmail.com
}

\begin{abstract}
RESUMO
Este artigo baseia-se em um desdobramento de uma dissertação de mestrado do Programa de Pós-Graduação em Ambiente Construído da Universidade Federal de Juiz de Fora. Este trabalho tem como objetivo investigar o período do dia com maior frequência e diversidade de pessoas nas praças de Juiz de Fora, assim como particularidades das mesmas, caracterizando a vitalidade nos Espaços Livres Públicos do município. Para isso, foi definida uma amostra de quatro praças da cidade com diferentes relações de renda e densidade demográfica do entorno. Foi realizada a contagem de pessoas in loco, em oito dias do ano distribuídos nas quatro estações do ano tanto em dias de semana quanto em dias de final de semana. Essas medições foram feitas nos turnos matutino, vespertino e noturno. A partir dos dados coletados percebeu-se que os dias com maior número de pessoas são os finais de semana do outono tanto no turno da tarde quanto no da noite. Esse trabalho tem como principal contribuição a demonstração das características dos espaços com maior vitalidade, de forma a indicar ao poder público o que deve ser levado em consideração no momento de projetar novas praças, assim como possíveis modificações nas já existentes.
\end{abstract}

Palavras-chave: Espaços Livres Públicos, Praças, Vitalidade Urbana, Urbanismo.

\begin{abstract}
This article is based on an unfolding of a master's thesis of the Post-Graduate Program in Built Environment of the Federal University of Juiz de Fora. This work aims to investigate the time of day with greater frequency and diversity of people in the squares of Juiz de Fora, as their particularities, characterizing the urban vitality in the Public Spaces of the city. For that, a sample of four squares with different income and demographic density. The counting of people in loco was carried out, in eight days of the year distributed in the four seasons of the year as much in days of the week as in days of the weekend. These measurements were taken in the morning, afternoon and evening shifts. From the data collected it was noticed that the days with the greatest number of people are the weekends of autumn both in the afternoon and in the evening. This work has as the main contribution to the demonstration of the particularities of
\end{abstract}

BERALDO, E.; SENRA, S; CASSANI, M; ALBERTO, K; GONÇALVES, A; NERY, L. Vitalidade em espaços públicos na cidade de Juiz de Fora. In: SIMPÓSIO BRASILEIRO DE QUALIDADE DO PROJETO NO AMBIENTE CONSTRUÍDO, 6., 2019, Uberlândia. Anais... Uberlândia: PPGAU/FAUeD/UFU, 2019. p. 1440-1449. DOI https://doi.org/10.14393/sbqp19129. 
spaces with bigger urban vitality, in order to indicate to the public power which should be taken into account when designing new squares, as well as possible modifications in existing ones.

Keywords: Public Spaces, Squares, Urban Vitality, Urbanism.

\title{
1 INTRODUÇÃO
}

Tendo em vista a diversidade de usos e características presentes nas praças brasileiras, esse estudo se propõe a analisar as praças públicas da cidade de Juiz de Fora. Este artigo tem como objetivo investigar o período do dia com maior frequência e diversidade de pessoas, que permite determinar a vitalidade urbana nos Espaços Livres Públicos de Juiz de Fora - MG. A cidade localiza-se no sudeste brasileiro a $21^{\circ} 45^{\prime} 51.01^{\prime \prime} \mathrm{S}, 43^{\circ} 21^{\prime} 1.01^{\prime \prime} \mathrm{W}$, com pouco mais de 560 mil habitantes, segundo o Instituto Brasileiro de Geografia e Estatística (IBGE, 2018). Esse tema surge de uma demanda específica de uma pesquisa ampla que envolve todas as praças da cidade. Com limitação de recursos que impediam a realização de diversas visitas em todas essas praças tornou-se necessário definir os períodos do dia com maior presença e diversidade de pessoas para otimizar o levantamento. Com essa definição todas as 104 praças poderiam ser estudadas in loco com maior precisão dos dados levantados.

Os resultados gerados por esta pesquisa podem contribuir ao demonstrar particularidades das praças de Juiz de Fora, indicando ao poder público quais espaços possuem maior vitalidade e suas características. Além disso, como objetivo secundário, poderá facilitar pesquisas posteriores na área referente aos Espaços Públicos de Juiz de Fora, no que se diz em relação ao horário de pesquisa. Dessa forma, os projetos de novas praças poderiam levar esses resultados em consideração no momento de planejamento.

\section{REVISÃO BIBLIOGRÁFICA}

O estudo dos espaços livres públicos (ELPS) é relevante pois estes apresentam funções vitais para uma cidade, são responsáveis pela circulação, lazer, contemplação, prática de atividades físicas e preservação (ROBBA e MACEDO, 2002). De acordo com Camillo Sitte, eles são responsáveis pela vida e convivência nas cidades (SITTE, 1992). Segundo Queiroga

\begin{abstract}
A possibilidade do contato interpessoal público, oferecida pela praça, permite o estabelecimento de ações culturais fundamentais, desde interações sociais até manifestações cívicas. Sendo assim, a praça potencializa a noção de identidade urbana que, dificilmente, o lazer na esfera da vida privada poderia proporcionar (QUEIROGA, 2001).
\end{abstract}

Autores relevantes no campo dos estudos da vida pública como Jane Jacobs (2001), Kevin Lynch (1981) e Jan Gehl (2010) quando caracterizam as praças públicas, convergem ao afirmar que estas são lugares de permanência que suportam uma variedade de usos, proporcionando assim uma diversidade de pessoas ao longo do dia.

A vitalidade urbana, é estudada por diversos autores do urbanismo. Para Camilo Sitte (1992), em seu livro A Construção Das Cidades Segundo Seus Princípios Artísticos, a praça é tão fundamental na geração de vitalidade urbana na cidade, ou seja, promove a circulação e presença de pessoas nas 
ruas, que uma cidade sem praça não deveria ser considerada cidade, pois, tratam-se de espaços simbolicamente importantes, referências cênicas na paisagem urbana, exercendo um relevante papel na identidade do bairro ou da rua.

A autora Jane Jacobs, em seu livro Morte e Vida das Grandes Cidades (1961), traz um estudo das praças de Nova lorque, trazendo o conceito de que uma boa praça, aquela que apresenta vitalidade urbana, deve ter diversidade de pessoas, variando idade, sexo e status social, diversidade de uso, função e horários de uso.

Kevin Lynch em sua obra "A boa forma da cidade" defende a diversidade de uso, funções e pessoas, como forma de se alcançar a vitalidade urbana, no caso das praças. O autor define que o sucesso da praça está diretamente relacionado com a sobreposição de usos ou disposição intencional.

\begin{abstract}
Mas o que a cidade viva realmente precisa é uma combinação de espaços públicos bons e convidativos e certa massa crítica de pessoas que queiram utilizá-los. Há incontáveis exemplos de lugares de alta densidade de edificações e espaços públicos ruins, que realmente não funcionam bem. Novas áreas urbanas são frequentemente densas e totalmente ocupadas, mas seus espaços urbanos são numerosos demais, muito grandes e muito ruins para inspirar qualquer um que se arrisque a utilizá-los (GEHL, 2010, p. 68).
\end{abstract}

Há uma grande variedade de estudos que podem ser desenvolvidos para ampliar o conhecimento sobre os ELPs. Uma dessas vertentes são os estudos sobre a vitalidade urbana, aqui entendida como a presença de pessoas nesses espaços. Esta pesquisa faz parte de uma dissertação de mestrado concluída no Programa de Pós-Graduação em Ambiente Construído (PROAC) da Universidade Federal de Juiz de Fora, em parceria com pesquisadores do Núcleo de Pesquisa Ágora da UFJF, na qual foi criada uma ampla base de dados em relação às praças da cidade.

\title{
3 METODOLOGIA
}

A metodologia utilizada neste trabalho foi dividida em cinco partes principais:

1. Mapeamento das praças de Juiz de Fora.

2. Seleção de quatro praças, segundo critérios de densidade e renda.

3. Definição de período de realização de contagem.

4. Contagens in loco.

5. Avaliação dos dados e comparação entre as praças.

\subsection{Mapeamento das praças de Juiz de Fora}

Para alcançar esse objetivo foi feito um levantamento de todas praças de Juiz de Fora. A prefeitura do município considera 169 Espaços Livres Públicos como praças. As praças foram georreferenciadas pelo programa ArcGIS e mapeadas em todo o município de Juiz de Fora. Entretanto, após consulta realizada no banco de dados do grupo de pesquisa Ágora da Universidade Federal de Juiz de Fora, constatou-se que dos 169 locais estabelecidos pelo poder público, apenas 104 poderiam de fato ser denominados como praças. 


\subsection{Seleção de quatro praças, segundo critérios de densidade e renda}

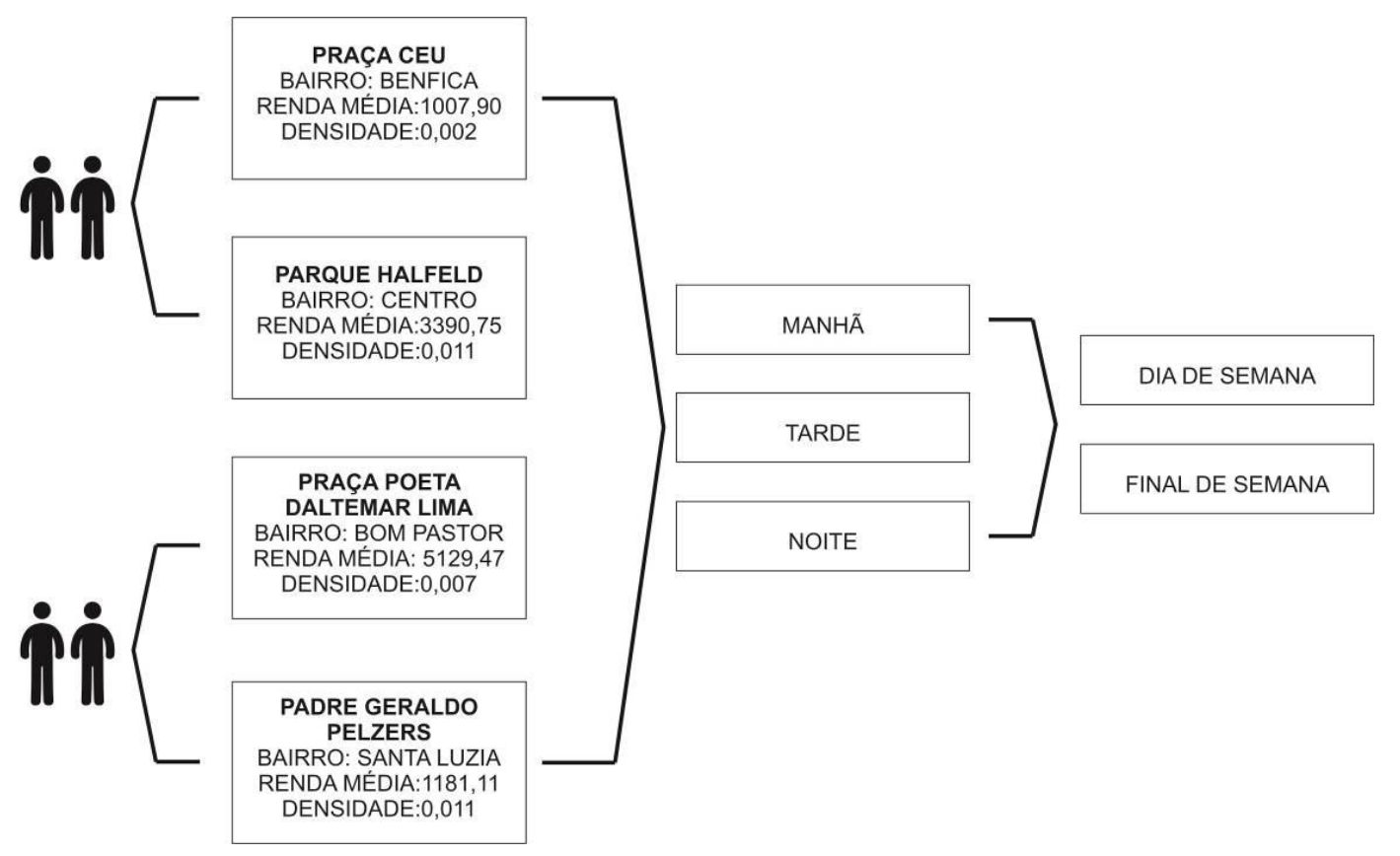

Figura 1 - Praças selecionadas com suas características de densidade e renda Fonte: Autora Senra (2019)

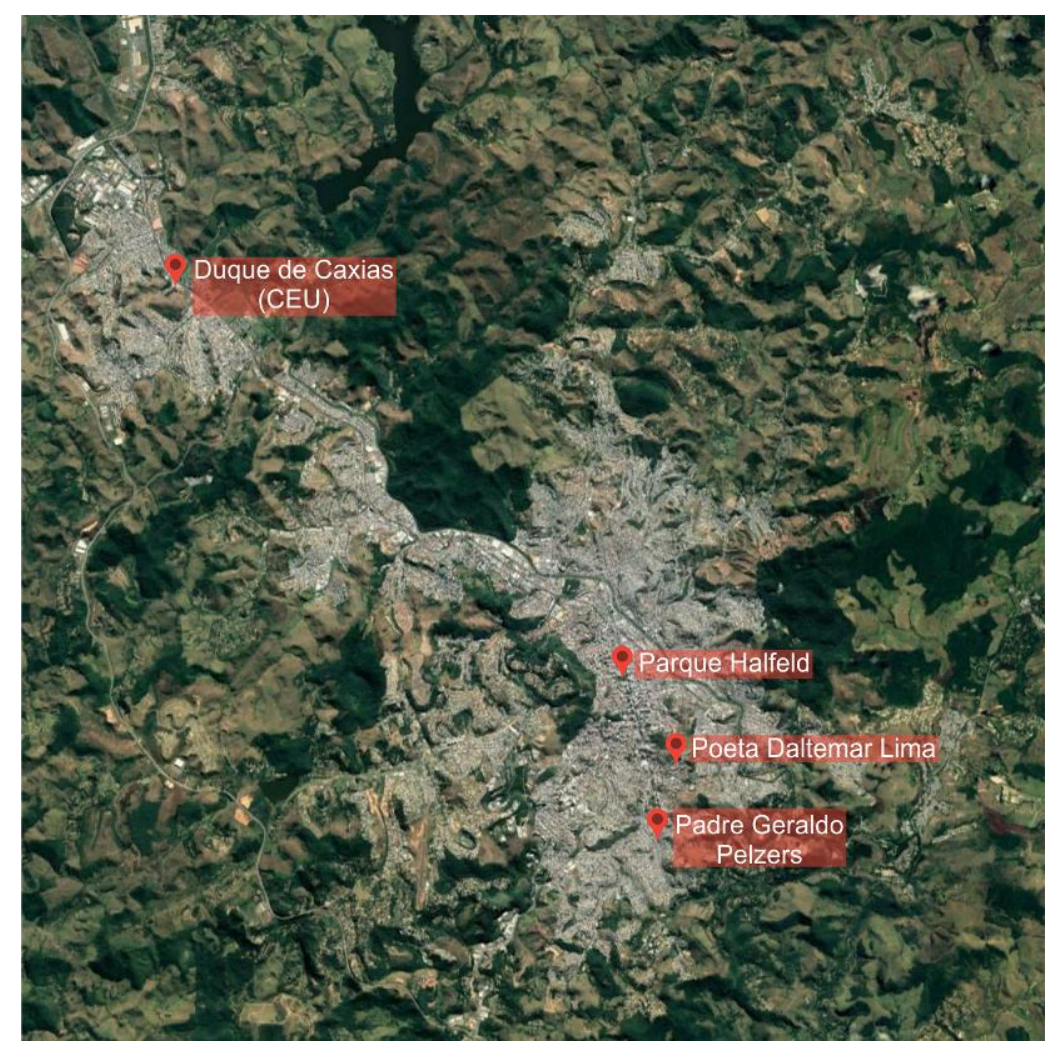

Figura 2 - Mapa de Juiz de Fora com localização das praças selecionadas Fonte: Autores (2019)

Levando em consideração esses locais, foi feita uma amostragem das praças da cidade a partir de critérios de densidade e renda estabelecidos pelo Censo Demográfico 2010 do IBGE (Instituto Brasileiro de Geografia e Estatística). Assim, duplas de pesquisadores foram estabelecidas para visitar 4 
praças do município, selecionadas por atenderem aos seguintes parâmetros: Parque Halfeld (alta renda e alta densidade), Poeta Daltemar Lima (alta renda e baixa densidade), Duque de Caxias (Praça CEU) (baixa renda e baixa densidade) e Padre Geraldo Pelzers (baixa renda e alta densidade), conforme demonstrado na Figura 1.

As praças avaliadas encontram-se distribuídas em diferentes bairros, garantindo variedade amostral. A Praça Parque Halfeld localiza-se no Centro de Juiz de Fora e a Praça Duque de Caxias (CEU) encontra-se no Bairro Benfica. Já a Praça Poeta Daltemar Lima pertence ao Bairro Bom Pastor, enquanto a Praça Padre Geraldo Pelzers está no Bairro Santa Luzia. A localização das mesmas é demonstrada na Figura 2.

Vale ressaltar que essas praças contam com diferenciais como áreas para prática de esportes, exercícios, playgrounds e atividades físicas. Algumas delas possuem quiosques de alimentação, bancas de revista e outros equipamentos.

\subsection{Definição do período de realização de contagem}

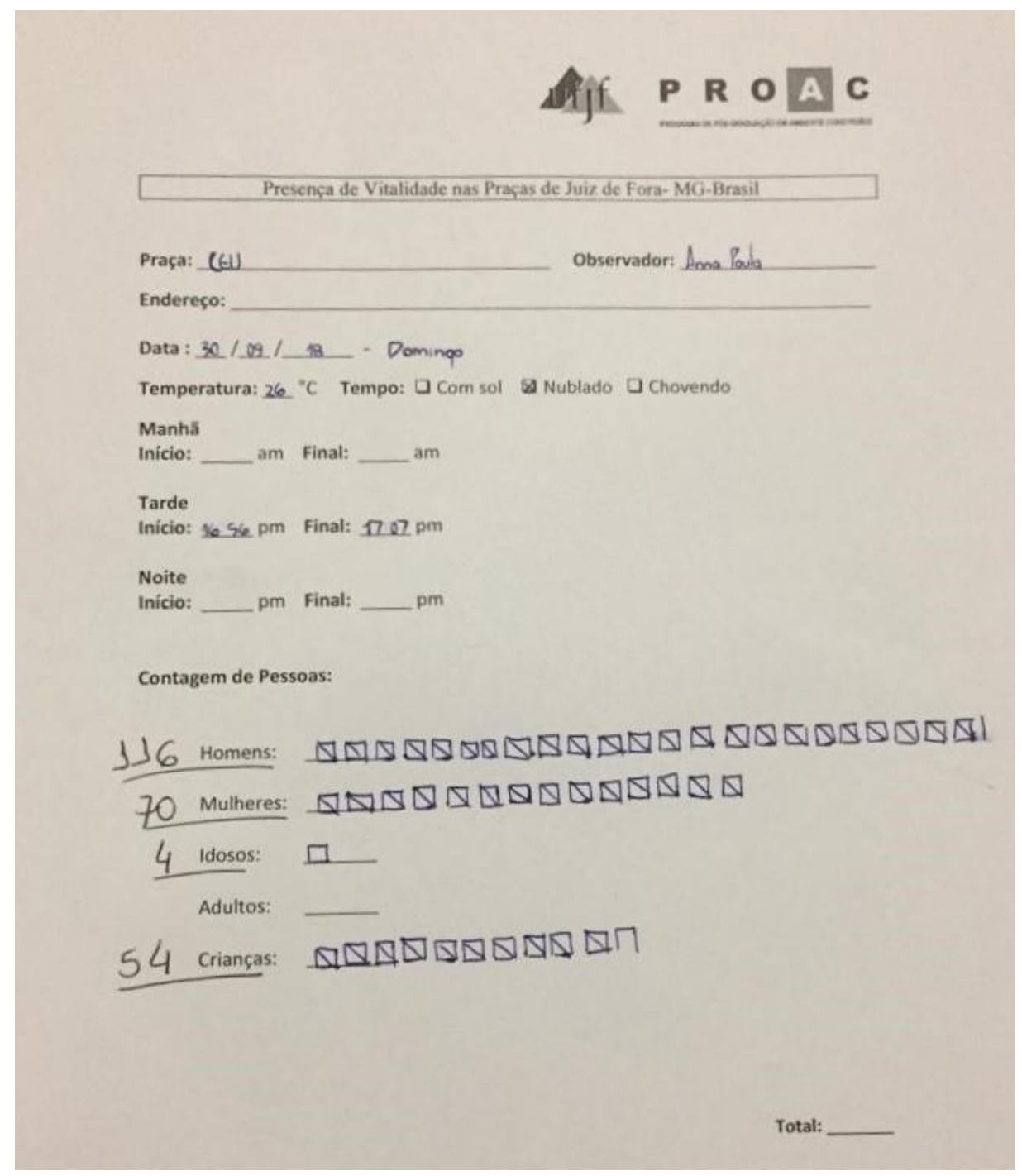

Figura 3 - Exemplo de protocolo aplicado -

Fonte: Autores (2019) 
Para acompanhar toda a variação na quantidade de pessoas, estabeleceuse que a contagem seria feita ao longo dos três turnos de dias de semana (úteis) e de finais de semana (sempre aos domingos) durante o período letivo. Trata-se, portanto, de visitas semanais nos turnos manhã, tarde e noite, e aos fins de semana também nos três turnos.

Foi criado um protocolo onde seriam anotados o nome da praça e do observador, endereço, data, temperatura, condição climática e horário inicial e final. Na parte da contagem propriamente dita, diferenciava-se as pessoas por sexo (homens ou mulheres) e idade (idosos, adultos ou crianças), conforme protocolo exemplificado na Figura 3.

\subsection{Contagens in loco}

O protocolo definia como público a ser computado homens, mulheres, idosos, adultos e crianças. A partir dessa definição foi realizada uma contagem de pessoas in loco para reconhecimento do período do dia em que as praças recebem um maior número de pessoas. As visitas foram feitas em dias com boas condições climáticas (sem chuva, com sol ou nublado) para não haver alterações de comportamento ou frequência nos Espaços analisados que, em sua maioria, são descobertos.

Após definir os períodos de contagem, as praças foram visitadas em dupla de pesquisadores e a contagem feita, cada pessoa fazia sua própria contagem individualmente. Em gabinete, os números encontrados foram analisados, para depois ser feita a média entre a contagem dos dois pesquisadores. Vale ressaltar que as diferenças entre os números coletados não foram significativas.

\subsection{Avaliação dos dados e comparação entre as praças}

A partir da coleta dos números pode-se compilar os dados. Os valores obtidos foram transferidos para planilhas de forma a facilitar a comparação entre as praças selecionadas. Essas planilhas geraram gráficos explicativos que correlacionam as quatro praças em estudo.

\section{RESULTADOS E DISCUSSÃO}

Os resultados dessa investigação foram divididos em cinco tópicos que abordam a variedade dos dados coletados:

1. Resultados por turno.

2. Resultados por praça.

3. Resultados por gênero e idade.

4. Resultados por estação.

5. Discussão.

\subsection{Resultados por turno}

Inicialmente os dados das 4 praças foram agrupados por turno. Percebe-se, no Gráfico 1, que a frequência de indivíduos nas praças foi aumentando ao longo do dia e que o turno com a maior presença de pessoas foi o da noite embora não tenha uma diferença muito significativa com o turno da tarde. 


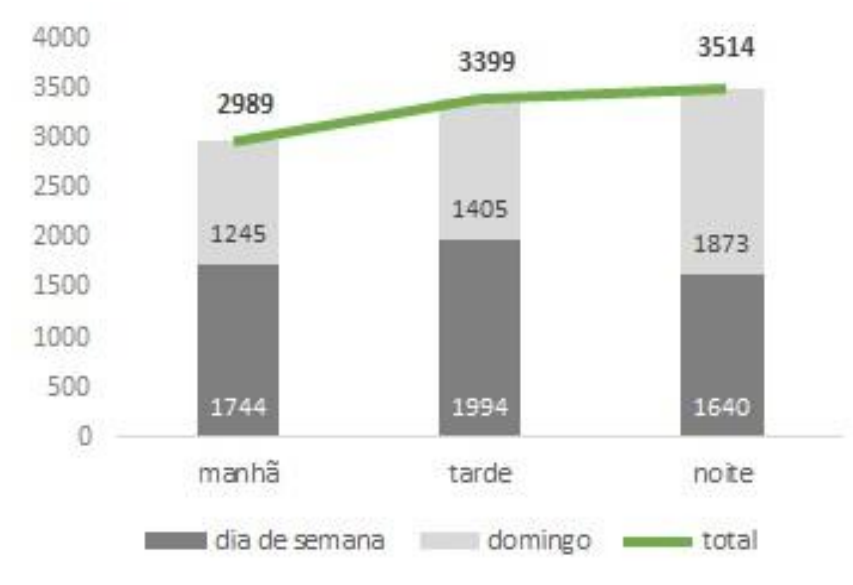

Gráfico 1 - Praças por turno Fonte: Autores (2018)

\subsection{Resultados por praça}

Em seguida, foi feita uma análise em cada uma das praças considerando a quantidade de pessoas em dias de semana típicos e aos domingos. Verificase, conforme Gráfico 2, que as praças possuem mais pessoas aos domingos. No entanto, percebe-se que o parque Halfeld se difere das demais nesse quesito. Isso se deve ao fato de estar situado em uma área central da cidade, sendo utilizado muitas vezes como passagem durante a semana, aumentando significativamente o número de usuários nesse período. Contudo, aos finais de semana, essa praça deixa de possuir um grande fluxo de indivíduos.

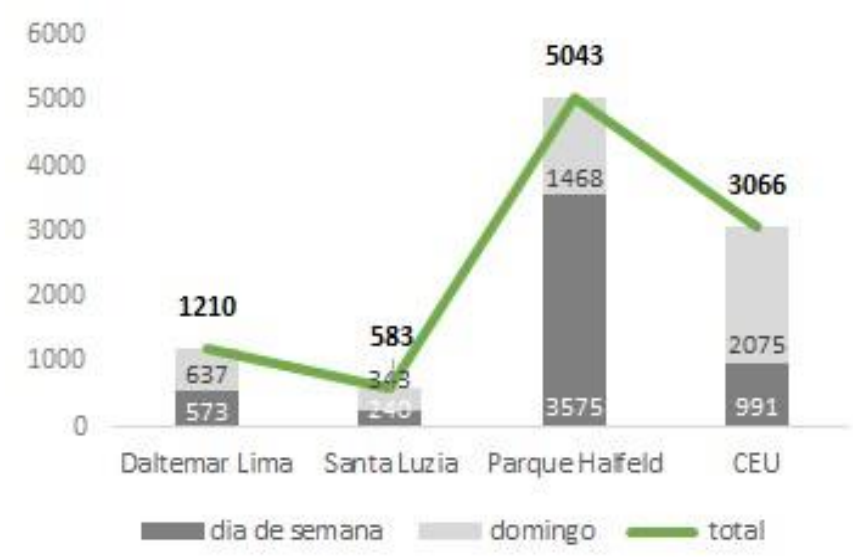

Gráfico 2 - Quantidade de pessoas em dias típicos e finais de semana Fonte: Autores (2018)

\subsection{Resultados por gênero e idade}

Posteriormente, foi averiguada a quantidade de pessoas por gênero e por idade, como é demonstrado no Gráfico 3.

Observando a diversidade de pessoas por gênero, conclui-se que os homens frequentam mais esses ambientes do que as mulheres em todos os turnos. Ao observar a questão da idade, infere-se que a presença de adultos é bem distribuída ao longo do dia, apesar de ainda ser maior à noite. Já os idosos frequentam mais as praças no turno da manhã e da tarde, enquanto as crianças se fazem mais presentes no período da noite. 


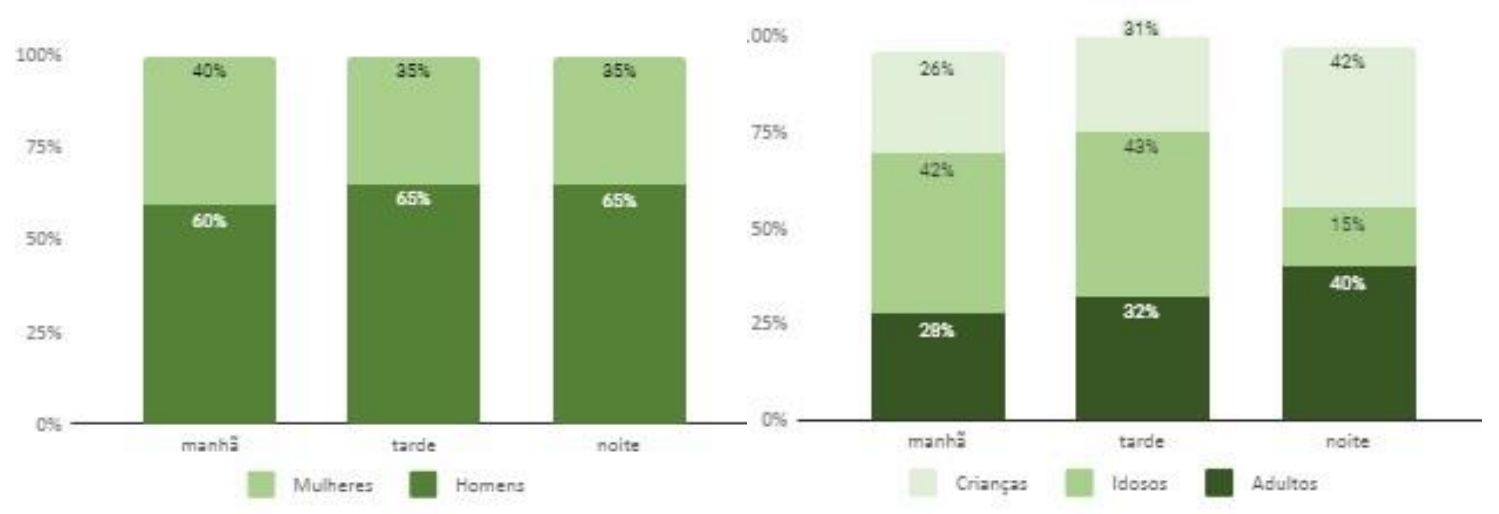

Gráfico 3 - Quantidade de pessoas por gênero e idade Fonte: Autores (2018).

\subsection{Resultados por estação}

Por último, os dados foram reagrupados para permitir a verificação da estação em que as praças apresentam maior número de pessoas, como é demonstrado no Gráfico 4.

Infere-se dessa análise que a estação do ano com maior presença de pessoas nas praças é o outono. Entretanto, esse resultado não foi tão significativo, uma vez que a diferença entre as estações foi relativamente pequena. No entanto, destaca-se uma redução do número de pessoas no verão.

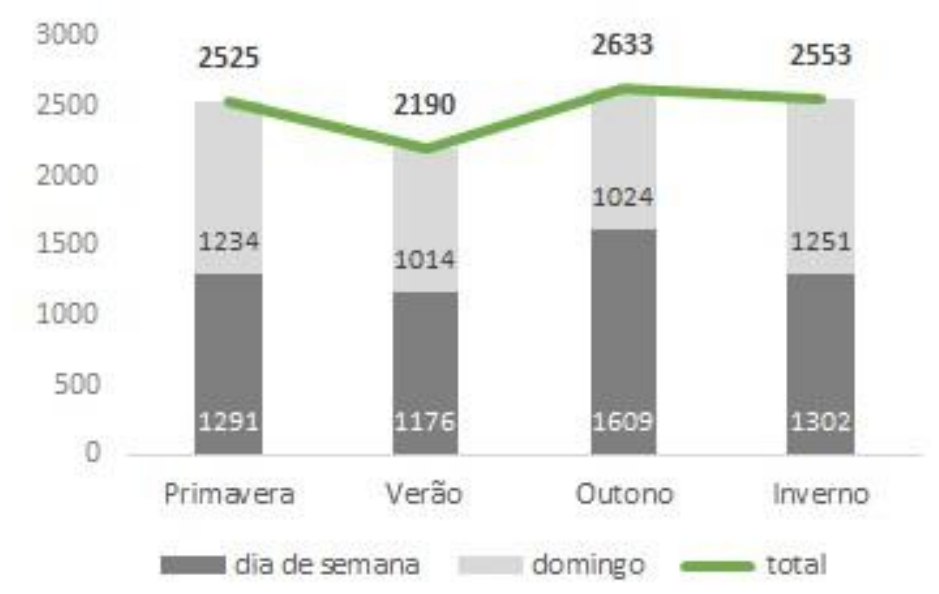

Gráfico 4 - Estações do ano -

Fonte: Autores (2018)

\subsection{Discussão}

Após análise geral, conclui-se que nesta cidade, as praças possuem maior vitalidade nos finais de semana. O Parque Halfeld torna-se uma exceção, visto que é um importante local de passagem no centro da cidade, portanto, as pessoas presentes na praça durante a semana, não necessariamente estão no local para de fato fazer uso do mesmo.

O turno da tarde é o que possui maior quantidade de pessoas e as praças são muito mais frequentadas por homens do que por mulheres. Essa questão deve ter um maior aprofundamento pois pode estar ligada à falta de segurança, o que sugere a importância de implementar políticas governamentais que garantam a segurança no espaço público. 
O fato das crianças estarem mais presentes à noite nesses espaços do que durante o dia possivelmente ocorre pelo fato das contagens terem sido feitas durante o período letivo.

A maior presença de pessoas ocorreu durante o outono, portanto essa seria a estação mais favorável para se realizar a contagem na cidade de Juiz de Fora. Entretanto, o resultado obtido não foi tão significativo quando comparado com outras estações, o que demonstra que as praças desse município possuem uma utilização bastante regular durante todo o ano.

\section{CONSIDERAÇÕES FINAIS}

Considera-se que o dia com maior quantidade de pessoas é o domingo. Já os turnos mais adequados são o da tarde e o da noite, preferencialmente ao entardecer (transição de um turno para o outro), uma vez que esse horário apresenta maior frequência e diversidade de pessoas. Como esta pesquisa foi feita em 4 praças do município, considerando observações realizadas em dias de semana e domingos em cada estação do ano, não é pertinente afirmar que em futuras pesquisas essa limitação de calendário deva ser adotada.

É importante observar que a definição de horários pertinentes para investigação dos Espaços Livres Públicos depende, não só de sua localização, mas principalmente dos objetivos da pesquisa, uma vez que o objeto de análise varia nos mais diversos estudos.

Esses resultados são relevantes para levar em consideração a qualidade dos Espaços Livres Públicos, com foco em praças urbanas, uma vez que demonstram o que deve ser levado em consideração pelo poder público da cidade de Juiz de Fora no momento de proposição e planejamento de novas praças.

\section{AGRADECIMENTOS}

Os autores agradecem aos grupos de pesquisa Ágora da Faculdade de Arquitetura e Urbanismo da Universidade Federal de Juiz de Fora por contribuir com o desenvolvimento da pesquisa. Agradecem também ao apoio do Conselho Nacional de Desenvolvimento Científico e Tecnológico (CNPq) e da Coordenação de Aperfeiçoamento de Pessoal de Nível Superior (CAPES).

\section{REFERÊNCIAS}

INSTITUTO BRASILEIRO DE GEOGRAFIA E ESTATíSTICA (IBGE). Censo Demográfico 2010. Rio de Janeiro: IBGE, 2010a. Disponível em: <https://censo2010.ibge.gov.br/>. Acesso em: 18 jan. 2019.

IBGE 2018. Cidades e Estados. Juiz de Fora. Disponível em: <https://www.ibge.gov.br/cidades-e-estados/mg/juiz-de-fora.html>. Acesso em: 18 jan. 2019.

GEHL, J. Cidades para pessoas. São Paulo: Perspectiva, 2010.

JACOBS, J. Morte e Vida das Grandes Cidades. São Paulo: Martins Fontes, 2001. LYNCH, K. A boa forma da cidade. Lisboa: Edições 70, 1981. 
QUEIROGA, E. F. A megalópole e a praça: o espaço entre a razão de dominação e a ação comunicativa. Tese (Doutorado em Arquitetura e Urbanismo) - Faculdade de Arquitetura e Urbanismo, Universidade de São Paulo, São Paulo, 2001.

ROBBA, F.; MACEDO, S. S. As Praças Brasileiras. São Paulo: Emesp, 2002.

SITTE, C. A Construção das Cidades Segundo Seus Princípios Artísticos. São Paulo: Ática, 1992. 